\title{
Rancang Bangun Alat Ukur Kelembaban Udara Berbasis Mikrokontroler ATMega328 dengan Sensor Serat OptikEvanescent Menggunakan Film Gelatin
}

\author{
Fitria Khairunnisa ${ }^{*}$, Harmadi \\ Laboratorium Fisika Elektronika dan Instrumentasi, Jurusan Fisika FMIPA Universitas Andalas \\ Kampus Unand, Limau Manis, Padang, 25163 \\ *fkphy1996@gmail.com
}

\begin{abstract}
ABSTRAK
Telah dirancang alat ukur kelembaban udara dengan sensor serat optik evanescent. Cladding serat optik dikupas dan diganti dengan film gelatin. Variasi panjang pengupasan cladding serat optik adalah $1 \mathrm{~cm}, 2$ $\mathrm{cm}$, dan $3 \mathrm{~cm}$. Kelembaban udara diukur dengan mengukur kelembaban udara di dalam humidity chamber. Alat ukur dirancang menggunakan sistem sensor yang terdiri dari laser dioda sebagai sumber cahaya, serat optik, fotodioda sebagai fotodetektor, dan mikrokontroler sebagai pengolah sinyal. Kelembaban diukur berdasarkan tegangan keluaran fotodioda. Semakin tinggi kelembaban udara maka semakin tinggi tegangan keluaran fotodioda. Hasil karakterisasi serat optik menunjukkan serat optik dengan panjang pengupasan $1 \mathrm{~cm}$ adalah yang paling optimum dalam mengindra kelembaban. Nilai sensitifitas sensor yang dirancang adalah $0,0186 \mathrm{~V} / \% \mathrm{RH}$ dengan koefisien determinasi $R^{2}=0,9457$. Persentase rata-rata kesalahan alat ukur yang dirancang adalah 1,56\% dibandingkan dengan alat ukur acuan (humidity meter).

Kata kunci: kelembaban udara, alat ukur, sensor serat optik, evanescent.
\end{abstract}

\section{ABSTRACT}

Humidity measuring instrument with evanescent optical fiber sensor has been designed. Cladding of optical fibers was tapered with gelatin film. Stripping length variation of fiber optic cladding were $1 \mathrm{~cm}$, $2 \mathrm{~cm}$, and $3 \mathrm{~cm}$. The humidity was measured by measuring the water vapor in the humidity chamber. The measuring instrument was designed using a sensor system which consists of a diode laser as a light source, optical fiber, photodiode as a photodetector, and a microcontroller as a signal processor. Humidity was measured based on the output voltage of the photodiode. The higher the humidity the higher the photodiode output voltage. The optical fiber characterization results showed that optical fiber with $1 \mathrm{~cm}$ stripping length were the most optimum in sensing humidity. The sensitivity value of the designed sensor was $0.0186 \mathrm{~V} / \% \mathrm{RH}$ with the coefficient of determination $R^{2}=0.9457$. The average percentage error of the instrument was $1.56 \%$ compared to the reference instrument (humidity meter). Keywords: humidity, measuring instrument, optical fiber sensors, evanescent.

\section{PENDAHULUAN}

Kelembaban udara merupakan ukuran jumlah uap air di udara. Perkembangan bahan elektronik dan serat optik telah mendukung dikembangkannya berbagai jenis sensor kelembaban udara dan teknik pengukurannya. Pengukuran kelembaban udara sangat penting di berbagai sektor perindustrian seperti industri pengolahan dan penyimpanan makanan, agrikultur, farmasi, biomedis, bahan kimia, ekologi, pemantauan kondisi cuaca atmosfer dan perindustrian lainnya (Alwis dkk., 2013).

Kelembaban udara dibedakan atas kelembaban udara absolut dan kelembaban udara relatif atau relative humidity $(\mathrm{RH})$. Pada saat ini, sensor kelembaban udara yang terdapat di pasaran atau yang sedang dikembangkan dalam penelitian laboratorium adalah sensor RH, yang selanjutnya dikategorikan menjadi tiga kelas yaitu tipe keramik (semikonduktor), sensor berbasis polimer organik, dan sensor hibrid organik/anorganik (polimer/keramik). Ketiga kategori sensor ini memanfaatkan perubahan sifat fisik dan sifat listrik elemen sensitif pada kondisi kelembaban atmosfer yang berbeda dari lingkungan sekitarnya (Farahani dkk., 2014). Jenis sensor RH lainnya yang masih terus dikembangkan adalah sensor serat optik. Sensor ini memanfaatkan perubahan sifat optis bahan terhadap perubahan kelembaban udara lingkungan sekitarnya (Maddu, 2006). Dalam 50 tahun terakhir, penginderaan serat optik telah menjadi salah satu cara yang sukses dan ampuh dalam teknologi penginderaan (Lou dkk., 2014). Udd (1990) menyatakan bahwa kelebihan sensor serat optik adalah tahan terhadap interferensi gelombang elektromagnetik. Selain kelembaban udara, serat optik juga digunakan untuk 
pengindraan terhadap perubahan fisis, kimia, maupun biologis pada objek yang akan diuji (Gholamzadeh dan Nabovati, 2008).

Sensor serat optik terdiri dari sensor serat optik ektrinsik, instrinsik dan evanescent (Frederick 1990). Sensor serat optik yang digunakan sebagai sensor kelembaban udara pada penelitian ini adalah dengan metode evanescent yaitu memodifikasi ulang cladding serat optik dengan cara mengupasnya dan menggantinya dengan film yang terbuat dari bahan gel. Bahan yang dibuat sebagai film adalah bahan yang sensitif uap air. Alwis dkk. (2013) membuat ulasan tentang penelitian-penelitian sensor kelembaban udara berbasis sensor serat optik dan dari ulasan ini dapat dilihat bahwa bahan yang terbuat dari film gelatin dapat digunakan pada alat ukur kelembaban udara karena memiliki range penginderaan yang besar serta waktu respon yang cepat.

Maddu dkk. (2006) melakukan karakterisasi terhadap sensor serat optik evanescent menggunakan film gelatin. Film gelatin merespon kelembaban dengan baik, regresi linear diatas 0,9 dan data yang diperoleh menunjukan bahwa film gelatin dapat berfungsi dengan baik sebagai elemen sensor kelembaban serat optik. Zhang dkk. (2008) juga menguji respon film gelatin sebagai sensor kelembaban dan didapatkan bahwa range penginderaan yang besar yaitu 9-94\% dengan waktu respon sekitar $70 \mathrm{~ms}$ dan memiliki sensitifitas yang baik. Menurut Maddu dkk. (2006) dan Zhang dkk. (2008), semakin pendek panjang pengupasan cladding maka keluaran sensor semakin optimum. Maddu dkk. (2006) mengupas cladding sepanjang $3 \mathrm{~cm}$ dan Zhang dkk. sepanjang 1,8 cm, maka pada penelitian ini dilakukan variasi panjang pengupasan cladding sebesar $1 \mathrm{~cm}, 2 \mathrm{~cm}$, dan $3 \mathrm{~cm}$. Penelitian Maddu dkk. (2006) dan Zhang dkk. (2008) hanya sebatas pembuatan dan karakterisasi sensor maka selanjutnya sensor evanescent dengan film gelatin dipakai pada alat ukur yang dirancang. Rancang bangun alat ukur kelembaban udara dengan sensor serat optik sebelumnya sudah pernah dilakukan oleh Wardana, dkk. (2011) menggunakan gel agarosa dengan sensitifitas sensor 0,0139 volt $/ \%$.

Berdasarkan uraian yang telah disebutkan, maka dilakukan penelitian untuk merancang bangun alat ukur kelembaban udara berbasis mikrokontroler ATMega328 dengan sensor serat optik evanescent menggunakan film gelatin. Hasil pengukuran yang berupa sinyal analog akan diubah menjadi sinyal digital oleh Arduino Uno yang di dalamnya terdapat mikrokontroler ATMega328 dan ADC (Analog to Digital Converter) internal lalu ditampilkan pada LCD (Liquid Crystal Display).

\section{METODE}

\subsection{Alat dan Bahan}

Alat dan bahan untuk keperluan pengupasan cladding serat optik berupa BF5R (sensor digital serat optik), pisau cutter, pisau pemotong serat optik, larutan aseton, dan amplas. Kabel serat optik dipotong sepanjang $21 \mathrm{~cm}$ menggunakan pisau pemotong serat optik, kemudian kabelnya dikupas menggunakan pisau cutter dan dicelupkan ke larutan aseton secara perlahan sambil digosok-digosok dengan tisu serbet, selanjutnya digosok dengan amplas berulang-ulang. Cara mengetahui bahwa cladding serat optik sudah terkupas adalah dengan menggunakan BF5R. Jika angka yang ditunjukkan oleh BF5R jauh dibawah 4000 artinya cladding serat optik telah terkupas. Indikasi lainnya adalah terjadi kebocoran di daerah sensing, cahaya yang merambat dapat dilihat oleh mata (Peslinof dkk., 2013).

Alat dan bahan yang digunakan untuk membuat rangkaian adalah breadboard, papan PCB, kabel jumper, timah, solder, resistor, trafo, potensiometer, kapasitor, dan pencabut timah solder. Alat dan bahan lainnya adalah humidity meter sebagai alat pengukur kelembaban acuan, Arduino Uno, LCD 2x16, laser dioda, dan fotodioda.

\subsection{Perancangan dan Karakterisasi Sensor Serat Optik}

Gelatin yang sensitif kelembaban digunakan sebagai pengganti cladding. Gel gelatin dibuat dengan cara mencampurkan $9 \mathrm{~g}$ bubuk gelatin dengan $30 \mathrm{ml}$ air pada temperatur $70^{\circ} \mathrm{C}$ pada hotplate sambil diaduk dengan pengaduk magnetik hingga larut merata. Selanjutnya larutan didinginkan di udara terbuka hingga mencapai temperatur $25^{\circ} \mathrm{C}$ dan larutan menjadi gel. Pelapisan (coating) inti serat optik dilakukan dengan teknik pencelupan (dip-coating) yaitu 
dengan mencelupkan bagian inti tanpa cladding ke dalam gel gelatin kemudian ditarik pelanpelan dari wadah gel, selanjutnya dibiarkan mengering sehari semalam. Pengeringan dapat dilakukan di dalam pendingin (freezer) agar pengeringan menjadi lebih cepat (Maddu dkk., 2006). Pengeringan yang dilakukan pada penelitian ini adalah dibiarkan di ruang terbuka sehari semalam.

Karakterisasi sensor serat optik yang pertama adalah melihat perbedaan tegangan keluaran dari sensor serat optik dengan cladding asli serat optik dan cladding menggunakan film gelatin di udara terbuka. Selanjutnya karakterisasi sensor serat optik yang cladding-nya sudah dilapisi film gelatin, yaitu menguji respon sensor dengan cara melihat tegangan keluaran fotodioda terhadap kelembaban udara. Pertama, uap air dialirkan kedalam humidity chamber dan dideteksi oleh serat optik kemudian tegangan keluarannya diukur dengan multimeter digital. Nilai sensitifitas sensor didapatkan dari fungsi transfer karakterisasi. Serat optik dengan sensitifitas paling optimum digunakan pada alat ukur yang dirancang.

\subsection{Karakterisasi Fungsi Transfer Arduino Uno}

Karakterisasi selanjutnya adalah melihat fungsi transfer yang diperoleh dari perbandingan kelembaban udara terhadap desimal ADC Arduino. Perubahan kelembaban udara mengakibatkan berubahnya nilai desimal ADC Arduino Uno. Fungsi transfer ini ditulis ke dalam bahasa pemrograman Arduino Uno untuk memproses pembacaan pada alat ukur yang dirancang. Adapun perancangan perangkat lunak sistem seperti yang ditunjukkan oleh Gambar 1.

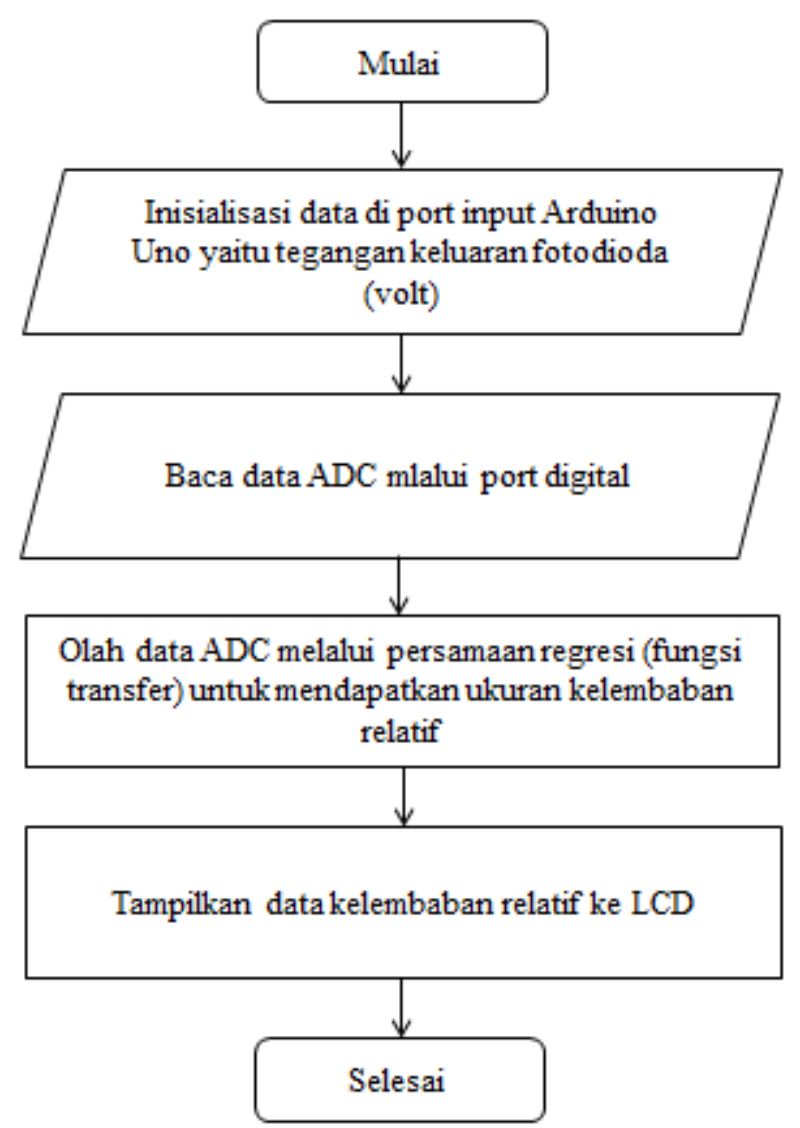

Gambar 1 Perancangan perangkat lunak sistem

Alat ukur kelembaban dirancang dengan sensor serat optik sebagai pengindra. Kabel serat optik yang digunakan berjenis FD 620-10. Sumber tegangan sistem ini yang terdiri dari laser dioda, fotodioda, dan LCD yaitu memanfaatkan catu daya +5 Volt dari Arduino Uno. Cahaya dari laser dioda merambat di dalam serat optik yang mengindra kelembaban, kemudian cahaya tersebut dideteksi dan diubah menjadi sinyal listrik oleh fotodioda. Sinyal analog dari 
fotodioda dikirim ke port $\mathrm{A}_{0}$ Arduino Uno dan diubah menjadi sinyal digital oleh ADC Arduino Uno. Setiap perubahan tegangan keluaran fotodioda diproses oleh Arduino Uno dan nilai kelembaban udara terbaca di LCD. Secara umum desain alat ukur kelembaban udara dapat dilihat pada Gambar 2.

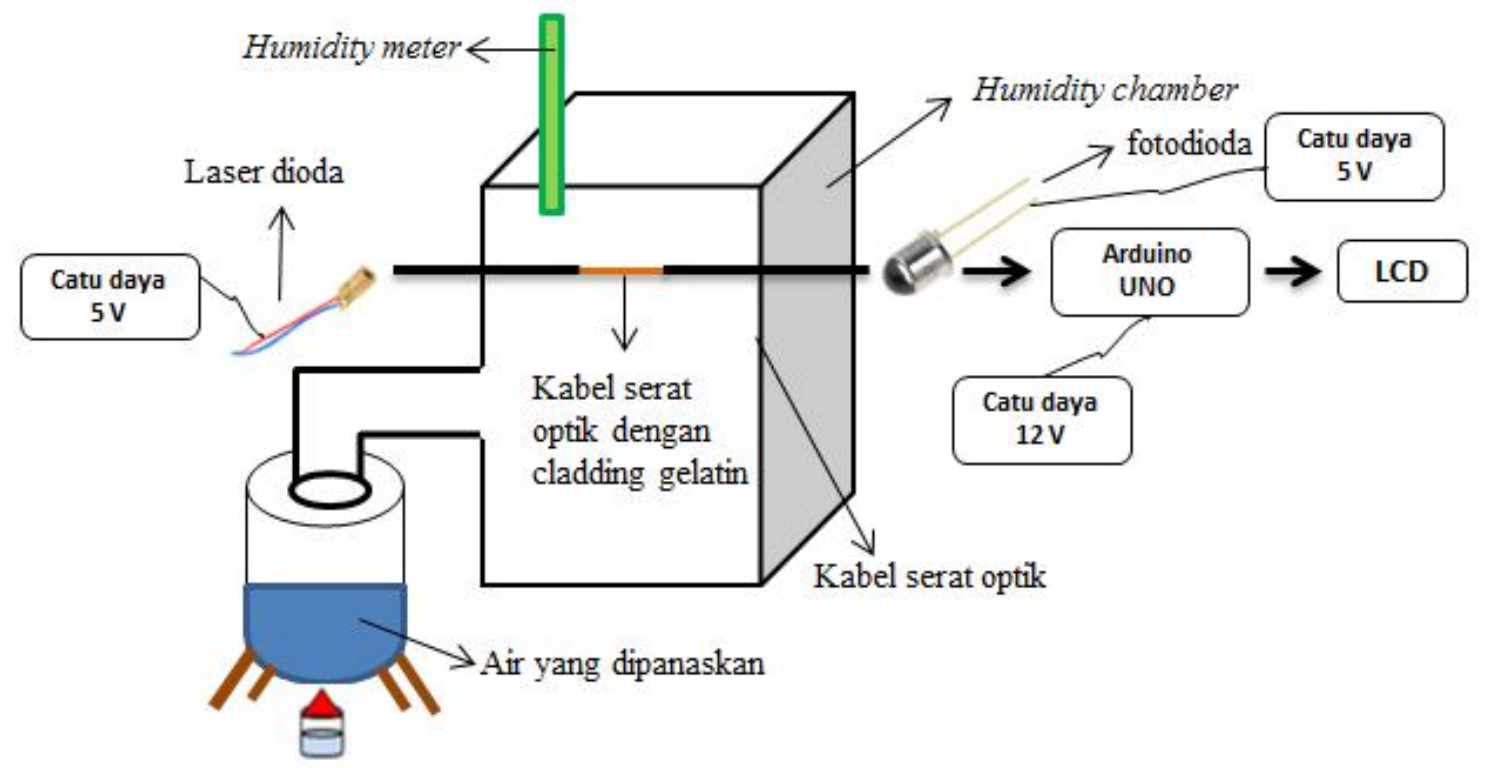

Gambar 2 Perancangan skematik bentuk fisik alat

Hasil pengukuran kelembaban udara ditampilkan pada LCD dan dibandingkan dengan alat ukur acuan (humidity meter). Perhitungan persentase kesalahan alat ukur dihitung dengan Persamaan 1.

$$
\text { Persentase kesalahan } e_{k}=\left[\frac{y_{0}-y_{k}}{y_{0}}\right] \times 100 \%
$$

dengan $Y_{0}$ adalah nilai sebenarnya (alat standar) dan $Y_{k}$ adalah nilai yang terbaca pada alat ukur.

\section{HASIL DAN DISKUSI}

\subsection{Karakterisasi Sensor Fotodioda}

Fotodioda pada penelitian ini digunakan untuk mengubah cahaya yang dikeluarkan serat optik menjadi besaran listrik. Karakterisasi sensor fotodioda dilakukan untuk mengetahui sensor yang digunakan bekerja sesuai dengan datasheet atau tidak. Gambar 3 menunjukkan bahwa hubungan antara tegangan keluaran fotodioda dengan jarak laser dan fotodioda adalah linear (berbanding lurus), yaitu semakin jauh jarak laser dioda dan fotodioda maka tegangan yang dihasilkan fotodioda semakin besar. Hal ini disebabkan oleh intensitas cahaya yang diterima fotodioda semakin kecil seiring jauhnya jarak laser dioda dan fotodioda sehingga resistansi fotodioda semakin besar dan menyebabkan besarnya tegangan keluaran dari rangkaian pembagi tegangan pada fotodioda. Hasil yang terukur sesuai dengan datasheet fotodioda. 


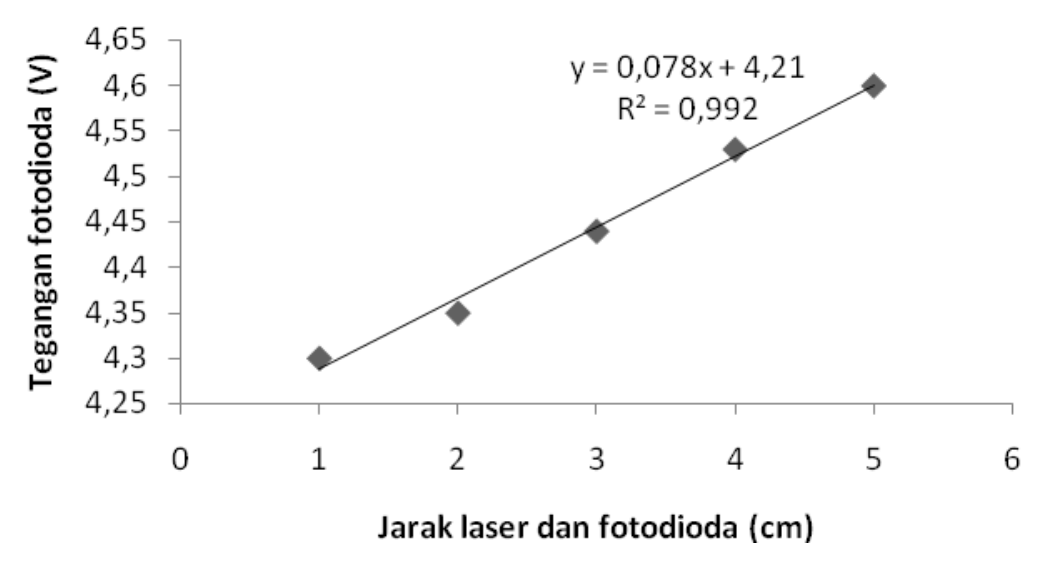

Gambar 3 Grafik hubungan tegangan keluaran fotodioda dengan jarak laser dan fotodioda

Persamaan yang diperoleh adalah $y=0,078 x+4,21$. Angka 0,078 merupakan besarnya sensitifitas sensor dan 4,21 merupakan offset dari sensor fotodioda. Koefisien determinasi $\left(R^{2}\right)$ yang diperoleh sebesar 0,9922 yang berarti memiliki linearitas yang cukup baik.

\subsection{Karakterisasi sensor serat optik}

Tabel 1 menunjukkan data hasil karakterisasi sensor serat optik yang pertama yaitu melihat perbedaan tegangan keluaran fotodioda dari serat optik dengan cladding yang berbeda. Serat optik dengan panjang pengupasan cladding paling besar $(3 \mathrm{~cm})$ menyebabkan tegangan keluaran fotodioda menjadi lebih besar. Hal ini disebabkan oleh semakin besar panjang pengupasan cladding maka semakin kecil intensitas cahaya yang dikeluarkan oleh serat optik karna rugi-rugi daya yang dihasilkan (Indra dan Harmadi, 2014) sehingga menyebabkan semakin besar tegangan keluaran fotodioda. Tegangan keluaran yang dihasilkan masingmasing cladding memiliki nilai yang berbeda karena indeks biasnya yang berbeda.

Tabel 1 Karakterisasi keluaran serat optik

\begin{tabular}{cccc}
\hline \multirow{2}{*}{ No } & \multirow{2}{*}{ Panjang pengupasan $(\mathbf{c m})$} & \multicolumn{2}{c}{ Rata-rata tegangan keluaran fotodioda $(\mathrm{V})$} \\
\cline { 3 - 4 } & 1 & Cladding serat optik & Cladding dengan film gelatin \\
\hline 1 & 2 & 3,87 & 4,59 \\
2 & 3 & 3,96 & 4,62 \\
3 & 4,30 & 4,64 \\
\hline
\end{tabular}

Karakterisasi selanjutnya adalah melihat sensitifitas sensor. Gambar 3 memperlihatkan grafik hubungan kelembaban udara terhadap tegangan keluaran fotodioda. Ssensor serat optik yang memiliki regresi paling akurat adalah serat optik dengan panjang pengupasan $1 \mathrm{~cm}$ yaitu $R^{2}=0,9538$. Selain itu, serat optik ini memiliki sensitifitas yang paling besar dilihat dari fungsi transfer yaitu $0,0186 \mathrm{~V} / \% \mathrm{RH}$.

Grafik menunjukkan bahwa semakin tinggi kelembaban udara maka semakin tinggi pula tegangan keluaran fotodioda. Hal ini disebabkan oleh kenaikan kelembaban udara membuat indeks bias film gelatin menurun karena mengalami pembengkakan saat menyerap uap air. Jika indeks bias cladding semakin menurun maka kedalaman penetrasi gelombang evanescent akan semakin besar sehingga cahaya masuk lebih banyak ke dalam cladding dan intensitas cahaya yang merambat semakin kecil. Hal ini sejalan dengan penelitian Zhang dkk. (2008) bahwa semakin tinggi kelembaban udara maka semakin kecil daya keluaran serat optik dan menurut Indra dan Harmadi (2014), penurunan indeks bias cladding akan menyebabkan intensitas cahaya yang ditransmisikan juga menurun. 

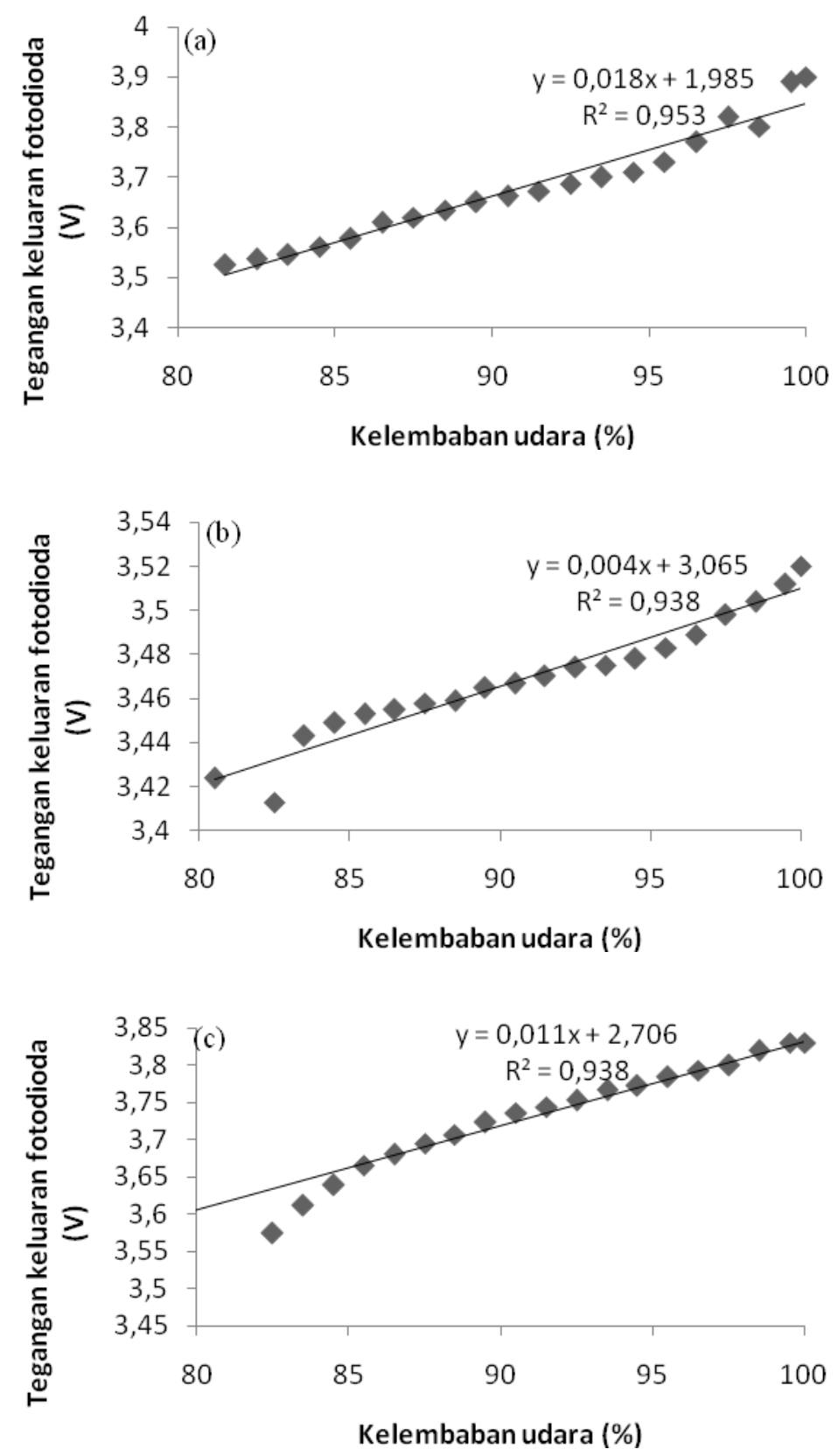

Gambar 4 Grafik kelembaban terhadap tegangan keluaran fotodioda pada sensor serat optik dengan panjang pengupasan (a) $1 \mathrm{~cm}$, (b) $2 \mathrm{~cm}$, dan (c) $3 \mathrm{~cm}$

\subsection{Karakterisasi Fungsi Transfer Arduino Uno}

Karakterisasi ini dilakukan untuk mendapatkan fungsi transfer dari sensor serat optik yang digunakan. Fungsi transfer ini akan ditulis dengan IDE dan di tanam didalam mikrokontroler ATMega328 yang terdapat di dalam Arduino Uno untuk mendapatkan hasil pengukuran kelembaban udara dalam satuan \% pada LCD. Grafik karakterisasi kelembaban udara terhadap desimal ADC dapat dilihat pada Gambar 5. 


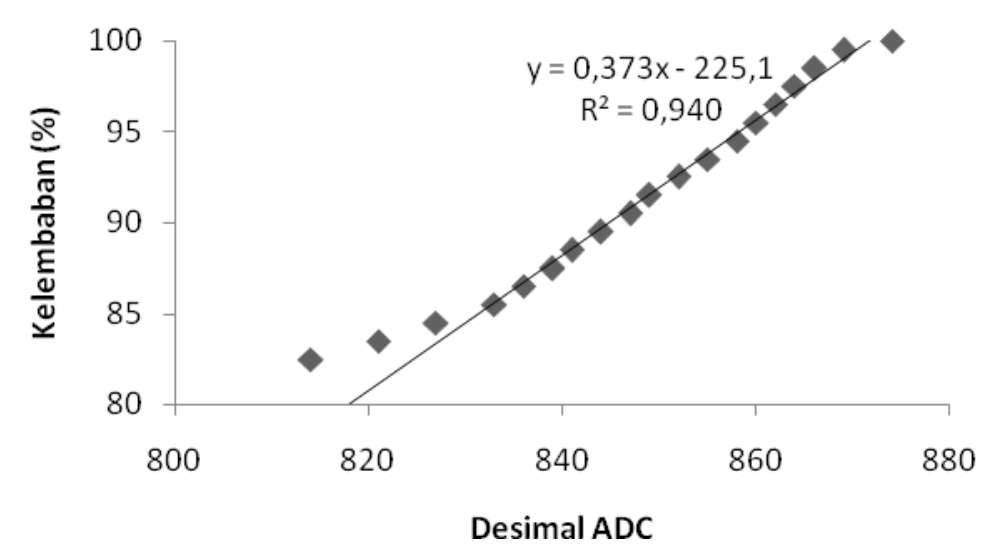

Gambar 5 Grafik kelembaban udara terhadap desimal ADC Arduino Uno

Persamaan yang diperoleh adalah $y=0,373 x-225,14$, dimana $x$ adalah tegangan masukan ADC dari keluaran fotodioda dan y adalah keluaran ADC yang merupakan nilai kelembaban udara terukur. Angka 0,373 merupakan besarnya faktor konversi desimal ADC dan -225,14 merupakan offset dari ADC Arduino Uno. Koefisien determinasi $\left(R^{2}\right)$ yang diperoleh sebesar 0,9407 yang berarti memiliki linearitas yang cukup baik.

\subsection{Pengujian Akhir Alat Ukur Kelembaban Udara}

Pengujian hasil pembacaan sensor ini dilakukan untuk melihat seberapa akuratnya tingkat ketelitian dari alat ukur untuk mendeteksi kelembaban udara yang dibandingkan dengan hasil pembacaan humidity meter. Tabel 2 menunjukkan bahwa hasil pengukuran alat ukur yang dirancang hampir mirip dengan alat ukur acuan dengan persentase kesalahan terbesar adalah $2,16 \%$. Sensor serat optik evanescent dengan film gelatin perlu ada fabrikasi yang teruji agar hasil pengukuran lebih akurat.

Tabel 2 Perbandingan pembacaan kelembaban pada LCD (sensor serat optik) dengan pembacaan pada humidity meter

\begin{tabular}{|c|c|c|c|}
\hline No & $\begin{array}{c}\text { Kelembaban udara alat } \\
\text { ukur yang dirancang } \\
\text { (\% RH) }\end{array}$ & $\begin{array}{c}\text { Kelembaban udara } \\
\text { humidity meter (\% RH) }\end{array}$ & $\begin{array}{c}\text { Kesalahan } \\
(\%)\end{array}$ \\
\hline 1 & 81,81 & 81,1 & 0,87 \\
\hline 2 & 86,58 & 85,0 & 1,86 \\
\hline 3 & 91,03 & 89,1 & 2,16 \\
\hline 4 & 92,20 & 91,0 & 1,32 \\
\hline 5 & 93,07 & 91,6 & 1,60 \\
\hline \multicolumn{3}{|c|}{ Rata-rata kesalahan } & 1,56 \\
\hline
\end{tabular}

\section{KESIMPULAN}

Alat ukur kelembaban udara telah sukses dirancang bangun. Sensor serat optik evanescent menggunakan film gelatin sudah dapat merespon kelembaban udara dengan nilai sensitifitas sensor paling optimum $0,0186 \mathrm{~V} / \%$ dan koefisien determinasi $R^{2}=0,9538$ pada panjang pengupasan cladding $1 \mathrm{~cm}$. Rata-rata persentase kesalahan alat ukur dibandingkan dengan alat ukur acuan (humidity chamber) adalah sebesar 1,56\%. Tegangan keluaran fotodioda sebanding dengan kenaikan kelembaban udara. Sensor serat optik evanescent perlu dilakukan fabrikasi agar hasil pengukuran lebih stabil dan akurat.

\section{DAFTAR PUSTAKA}

Alwis, L., Sun, T., Grattan, K.T.V., Elsevier, 4052-4074 (2013).

Faharani, H., Wagiran, R., Hamidon, M.N., Sensors, 7881-7939 (2014).

Frederick, C.A., Fiber Optic Handbook for Engineers and Scientist (McGraw-Hill, Inc, New York, 1990). 
Gholamzadeh, B. dan Nabovati, H., World Academy of Science, Engineering and Technology Journals, 1107 (2008).

Indra, A.T., dan Harmadi, Jurnal Fisika Unand, 8-12 (2014).

Lou, J., Wang, Y., Tong, L., 2014, Sensors, 5823-5844 (2014).

Maddu, A. Modjahidin, K. Sardy, S. Zain, H, Makara, 45-50 (2006).

Udd, E., Fiber Optic Sensor An Introduction for Engineers and Scientist (John Wiley \& Sons, Inc, New Jersey, 1990).

Zhang, L., Gu, F., Lou, J., Yin, X., Tong, L., Optic Express, 13349-13353 (2008).

Wardana, M.A., Muntini, M.S., Hatta, A.M., Perancangan dan Pembuatan Sistem Pengukuran Kelembaban Menggunakan POF (Polymer Optical Fiber) http://digilib.its.ac.id/public/ITS-Master-17769-1109201001-paperpdf.pdf (2011) 